Internal basic research, external basic research and the technological performance of pharmaceutical firms

Bart Leten, Stijn Kelchtermans and René Belderbos

DEPARTMENT OF MANAGERIAL ECONOMICS, STRATEGY AND INNOVATION (MSI) 


\title{
Internal Basic Research, External Basic Research and the Technological Performance of Pharmaceutical Firms*
}

\author{
Bart Leten $^{1,}$, Stijn Kelchtermans ${ }^{1,2}$ and René Belderbos ${ }^{1,3,4}$ \\ ${ }^{1}$ Katholieke Universiteit Leuven (Belgium) \\ ${ }^{2}$ Hogeschool Universiteit Brussel (Belgium) \\ ${ }^{3}$ UNU-MERIT (The Netherlands) \\ ${ }^{4}$ Maastricht University (The Netherlands)
}

\begin{abstract}
We evaluate the impact of basic research on pharmaceutical firms' technological performance, distinguishing between internal basic research and the exploitation of external basic research findings. We find that firms increase their performance by engaging more in internal basic research, in particular if basic research is conducted in collaboration with university scientists. The exploitation of external basic research improves performance, while the magnitude increases with firms' involvement in internal basic research. Hence, internal basic research and the exploitation of external basic research are complements, suggesting that internal basic research provides firms with the skills to exploit external basic research more effectively.
\end{abstract}

Keywords: Basic Research, Industrial Innovation, Pharmaceutical Industry

\footnotetext{
* The authors acknowledge financial support from EU FP7 grant number SSH7-CT-2008-217436. Corresponding Author: Bart Leten, Department of Managerial Economics, Strategy and Innovation, Faculty of Business and Economics, Katholieke Universiteit Leuven, Naamsestraat 69, Leuven, Belgium.
} 


\section{Introduction}

There is abundant evidence of the important role of basic research in driving innovation, economic growth and welfare (Mansfield, 1980; Jaffe, 1989; Griliches, 1986; Adams, 1990; Salter and Martin, 2001). Basic research can be defined as activities that are directed towards the general advancement of men's knowledge about the physical world, but without specific commercial objectives (Nelson, 1959). These activities expand the knowledge base available for firms on which they can draw in their technological activities (Klevorick et al, 1995). Numerous important technical inventions were the direct result of advances in scientific knowledge resulting from basic research. ${ }^{1}$ To what extent it is rational for firms to be involved themselves in basic research has been subject to a long debate among economists. Nelson (1959) argues that firms are reluctant to invest in basic research due to high degrees of uncertainty, long time frames to bear fruit, and appropriability problems. Appropriability problems result from the fact that the outcome of basic research, i.e. knowledge, is believed to be (at least partly) a public good and therefore freely available to other firms, including those that did not invest in basic research themselves (Arrow, 1962). Rosenberg (1990), on the other hand, argues that, despite these difficulties, there are rational reasons for private firms to conduct internal basic research activities. Firms that perform basic research may, for example, benefit from first-mover advantages, and improve the efficiency of their technology activities by developing a deeper understanding of the phenomena under study. In addition, internal basic research capabilities will help firms to develop the absorptive capacity (Cohen and Levinthal, 1990) to monitor, interpret, appraise, and utilize findings emanating from basic research conducted outside the firm.

A small number of empirical studies have examined the impact of basic research on the technological performance of firms, providing mixed results. These studies focused either on the role of internal basic research, or on the effect of the usage of external basic research findings. Among the first studies, Gambardella (1992) found that US pharmaceutical firms with stronger in-house basic research skills produced a greater number of inventions. Cockburn and Henderson (1998) found positive effects of internal basic research only when this research was undertaken

\footnotetext{
${ }^{1}$ A famous example is the development of the transistor at the Bell Telephone Laboratories in 1948 as a result of basic research activities of company scientists on the workings of semiconductor materials (Nelson, 1962).
} 
in collaboration with university scientists. Lim (2004) found no effect of internal basic research on the patenting performance of pharmaceutical firms, while a counterintuitive negative effect was found for semiconductor firms. ${ }^{2}$ Using a sample of pharmaceutical and biotechnology firms, Fabrizio (2009) found that firms that conduct more basic research tend to produce inventions (patents) of higher value. A second set of studies examined the effect of the exploitation of external basic research findings (measured by citations to scientific literature in firm patents) on the value of firm inventions (forward citations of patents). Fleming and Sorenson (2004) identified a positive relationship between patent value and citations to scientific literature in fields where technology development is complex. For a sample of Belgian firms, Cassiman et al (2008) similarly found qualified support for the effect of external basic research on firm innovation. While they did not find a direct relationship between the presence of scientific references on patent documents and patent value, results were indicative that exploiting external basic research did increase the value of firms' other patents, in particular when firms were also active in establishing broader linkages with scientific research.

This paper extends and improves on this body of prior empirical work on the importance of basic research for firms' innovative performance. Our study is the first to jointly examine the impact of self-performed basic research (internal basic research) and the usage of external basic research findings in firms' technology activities (external basic research) on firms' technological performance. This allows us to explicitly test for potential complementarities between both types of basic research activities. In particular, we test whether firms with stronger internal basic research capabilities are better positioned to benefit from the usage of external basic research findings in their technology development activities. Second, we use more accurate indicators for basic research than prior empirical work. Prior studies have predominantly used the number of corporate scientific articles as proxy for internal basic research activities, and references to scientific articles in firm patents as proxy for the exploitation of external basic research findings in firms' technology activities. However, scientific articles are an imperfect measure of basic research because a large share of these articles report on applied research activities related to clinical trials (Hicks, 1994). Using information on the specific journals in which firms' scientific

\footnotetext{
${ }^{2}$ While the study of Lim (2004) makes a distinction between firms' publications in basic and applied research journals, his analysis of the relationship between firms' patent performance and publication activities did not control for difference in firm R\&D inputs, which may partly explain the heterogeneity in the empirical results.
} 
articles are published and the CHI classification scheme for basic versus applied research (Hamilton, 2003), we construct more accurate indicators of internal basic research and the exploitation of external basic research by relying on the subset of corporate scientific articles appearing in journals that are classified as dealing with basic research.

Our study uses panel data (1995-2002) on the patent and publication activities of 33 of the world's largest R\&D spending pharmaceutical firms. Applying fixed effects models and controlling for R\&D inputs and past innovative performance, we find that firms engaging in internal basic research increase their technological performance, in particular when these activities are undertaken in collaboration with universities. In addition, we observe that firms can improve their technological performance by more frequently exploiting external basic research findings in their technology activities. The impact of the exploitation of external basic research on firms' performance increases when firms do more internal basic research, confirming that internal basic research and the exploitation of external basic research are complements.

The remainder of the paper is organized as follows. The next section provides a brief overview of the existing literature on the relationship between basic research and innovation and describes the research priors. We proceed with a description of the data and the empirical model in section three. The empirical results are discussed in section four and in the final section, we conclude on the main findings and suggest avenues for further research.

\section{Private Firms and Basic Research}

\section{Background}

Basic research has received many definitions (Rosenberg, 1990). We adopted the definition of the National Science Foundation (NSF) where basic research is defined as the systematic study directed towards greater knowledge or understanding of the fundamental aspects of phenomena and observable facts without specific immediate commercial applications in mind, although research may be in fields of present or potential commercial interest of those performing the research activities (NSF, 2009). Applied to the pharmaceutical industry, basic research includes 
attempts to reveal the mechanisms and processes of diseases, but does not include applied research activities such as compound screening, clinical trials and dosage testing (Lim, 2004). Basic research activities conducted by firms are concentrated in two different respects. First, the majority of basic research is conducted in a small number of industries such as pharmaceuticals, chemicals, electrical machinery and aerospace (Mansfield, 1980; Rosenberg, 1990). These sectors are called 'science-based industries' in Pavitt's (1984) classical sector taxonomy. Second, within these sectors a handful of firms perform a large share of the basic research activities. These firms are typically large firms with diverse product and technology portfolios and large R\&D laboratories. These firms are more confident that they will be able to put both anticipated and unexpected findings from basic research into commercial use (Nelson, 1959).

Basic research is a process of learning of the physical world that generates knowledge which is available for firms to draw upon in their applied technology activities (Klevorick et al, 1995; Matutes et al, 1996). Mansfield (1995 \& 1998) examined the importance of basic research for firms' technology activities by surveying samples of US firms across different industries. He found that, during the period 1975-1985, 11\% of firms' new products and 9\% of new processes could not have been developed (or with substantial delay) in the absence of basic research conducted by universities. These numbers are higher for the period 1986-1994 (respectively 15\% and 11\%), suggesting that basic research findings increase their importance for industrial R\&D. Another indication of the growing reliance of industrial technology activities on (basic) scientific knowledge can be found in the analysis of citations to scientific literature in patent documents. For instance, Narin et al (1997) reported a threefold increase in the number of citations to scientific literature in industrial patents in the United States during the early and mid 1990s.

\section{Basic Research in the Pharmaceutical Industry}

Basic research is an important source of knowledge for industrial innovation in many industries, but particularly in the pharmaceutical industry (McMillan et al, 2000). Patents in drugs and medicine classes cite significantly more scientific articles than patents in other classes (Narin et al, 1997) and cite basic scientific research more heavily (Narin and Olivastro, 1992). The strong reliance of pharmaceutical firms on basic research becomes also apparent from the case histories of the discovery of 21 important drugs described by Cockburn and Henderson (1998). 
Fundamental insights in basic research played a role in the discovery of sixteen of these drugs. The link between basic research and drug discovery has increased over time (Lim, 2004). Pharmaceutical firms have moved away from randomly screening a large number of potentially useful compounds against a certain disease, towards a more systematic approach called rational drug design. This approach involves exploiting knowledge about the biochemical mechanisms causing a disease to identify and develop compounds that inhibit the mechanisms (Pisano, 1997).

Basic research has become part of the drug discovery processes in most pharmaceutical firms. Based on case studies of US pharmaceutical firms, Gambardella (1992) has however shown that pharmaceutical firms pursue different strategies with respect to the importance given to basic research. For example, while Merck invested strongly in internal basic research and used this knowledge to exploit and further build on externally generated basic research findings, BristolMyers on the other hand has had only modest internal basic research skills (Gambardella, 1992).

\section{Research Priors}

The purpose of the current study is to examine whether differences in internal and external basic research strategies of pharmaceutical firms translate in differences in technological performance, while examining the potential complementarity between internal and external basic research. Below we formulate a number of priors on these relationships.

\section{Exploitation of External Basic Research}

Company researchers often consult scientific literature to solve technical difficulties in their technology activities (Allen, 1977; Gibbons and Johnston, 1974). Organizations that frequently consult and exploit external basic research findings in their technology activities are expected to develop a deeper understanding of the fundamental principles of the phenomena under study (Rosenberg, 1990). Basic scientific knowledge allows firms to anticipate the results of research experiments without performing them, helping firms to prioritize research avenues and to avoid costly and time consuming research trials that lead to low-value outcomes (Fabrizio, 2009). In other words, basic scientific knowledge informs firms on the success probabilities of different directions to conduct applied research (Fleming and Sorenson, 2004; Cassiman et al. 2008). Basic scientific knowledge also helps firms to evaluate the outcomes of applied research and to 
perceive its implications (Rosenberg, 1990). These arguments suggest that firms that exploit more external basic research findings in their technology activities may be able to increase their technological performance.

\section{Internal Basic Research}

Firms that conduct internal basic research benefit from the scientific knowledge that is generated by these research activities in a similar way as firms that exploit external basic research findings. Basic scientific knowledge serves as a map of the technological landscape which firms search for inventions, guiding them towards the most promising research directions (Fleming and Sorenson, 2004). Performing in-house basic research has however additional advantages for firms' technological performance. First, internal basic research capabilities may act as an admission ticket to R\&D partnering with universities and public research organizations (Liebeskind et al, 1996; Cockburn and Henderson, 1998). Internally performed basic research activities demonstrate the scientific competences firms need in order to enter into relationships of information exchange with public sector scientists (Hicks, 1994). Second, internal basic research may act as a powerful recruiting tool, since the scarce highest quality researchers ('stars') are reluctant to work for firms in which they are not allowed to do basic research and publish scientific findings (Henderson and Cockburn, 1994; Hicks, 1999; Narin \& Breitzman, 1995). Publishing is one of the most important means for scientists to establish their reputations (Stephan, 1996) and corporate scientists are found to be willing to accept lower wages in exchange for the permission to conduct and publish scientific research (Stern, 2004). It has been shown that employing star scientists can have a large positive impact on the technological performance of firms (Zucker et al, 2002; Furukawa and Goto, 2006).

Taken together, the arguments above suggest that firms can increase their technological performance by conducting internal basic research activities. There are reasons to believe that the benefits of internal basic research are larger when research activities are conducted in collaboration with universities. Collaboration with university scientists often leads to extensive debate, exchange of ideas and discussions. This provides firms with access to tacit knowledge of university scientists, which is not provided in journal articles (Arora and Gambardella, 1990; Cockburn and Henderson, 1998). Furthermore, these collaborations may help firms to get access 
to relevant codified scientific research of university scientists that is not yet published, allowing firms to build faster on recent research findings in their own research activities (Fabrizio, 2009).

Hence, firms that conduct a greater share of their internal basic research activities in collaboration with universities may be able to benefit most, in terms of technological performance, from internal basic research.

\section{Complementarity Between Internal Basic Research and External Basic Research}

External basic research findings are not a free input to firms' own research activities (Rosenberg, 1990). As Cohen and Levinthal (1990) have noted, learning is a cumulative, incremental process which is influenced by capabilities that are already present at the individual and organizational level. Individuals learn through a process whereby new events are stored in their memories by establishing linkages with pre-established concepts and ideas. An organization's ability to learn depends, at least in part, on the ability of its individual members to learn as organizational learning involves the joint contribution of individual members to solve problems (Helfat, 1994). Therefore, the ability of organizations to learn from external research findings depends on the commonality between the organizations' internal knowledge base and the external research findings which firms intend to exploit in their technology activities (Teece et al, 1997). Hence, firms that want to take advantage of research conducted outside their organizations need to invest in an 'absorptive capacity' in the sense of accumulating knowledge and skills to understand and utilize externally generated knowledge (Cassiman and Veugelers, 2006; Lokshin et al, 2008). The creation of an 'absorptive' capacity for external basic research findings, involves the employment of a cadre of scientists and granting them the freedom to perform basic research (Pavitt, 1991). Based on the absorptive capacity argument, firms with stronger in-house competences in basic research may be better equipped to benefit from the exploitation of external basic research findings in their own technology activities.

\section{Data and Empirical Model}

We constructed a panel dataset on the patent and publication activities of 33 large R\&D spending firms in the pharmaceutical industry. The sample firms are selected as top R\&D spenders in the 
pharmaceutical industry from the '2004 EU Industrial R\&D Investment Scoreboard'. This scoreboard lists the top 500 corporate investors in R\&D whose parent is located in the EU, and the top 500 companies whose parent is located outside the EU (mainly US and Japan), based on corporate R\&D expenditures in 2003. The sample firms have headquarters in the United States, Europe and Japan and are observed over a period of eight years (1995-2002). The sample includes pharmaceutical firms and three large biotechnology firms (Chiron, Amgen and Genzyme). ${ }^{3}$ The R\&D investments of the sample firms totaled 40.2 billion US dollars in 2002. The smallest company R\&D budget in our sample amounts to 175 million (Sepracor) and the largest R\&D budget reaches almost 6 billion US dollars (Pfizer).

Our measure of the technological performance of the firms is based on patent data. There are numerous advantages of the use of patent indicators (Pavitt, 1985; Basberg, 1987; Griliches, 1990): patents contain detailed information on the technological content, owners and prior art of patented inventions; patent data are objective in the sense that they have been processed and validated by patent examiners; and patent data are easily available from patent offices and cover long time series. Like any indicator, patent indicators are also subject to a number of drawbacks: not all inventions are patented and those that are patented vary in their technical and economical value (Trajtenberg, 1990; Lanjouw et al, 1998; Gambardella, 2008). The first problem can be addressed by limiting patent analyses to industries with high patent propensities and studying firm-level patent time series. ${ }^{4}$ The 'value' problem can be taken care of by weighting patent counts by the number of forward patent citations received by these patents (Trajtenberg, 1990; Harhoff et al, 1999; Hall et al, 2005). Both approaches are followed in this paper.

Since company names in patent databases are not unified and patents may be applied for under names of subsidiaries or divisions of a parent firm, we collected patent data at the consolidated parent firm level. Therefore, we searched, for each parent firm, for patents under the name of the parent firm as well as all their majority-owned subsidiaries. For this purpose, yearly lists of companies’ subsidiaries included in corporate annual reports, yearly 10-K reports filed with the

\footnotetext{
${ }^{3}$ Arora et al (2009) showed that these older, large, biotech firms display strategic behavior and innovation performance similar to pharmaceutical firms. Removing the three biotech firms from the sample did not have a material impact on the empirical results.

${ }^{4}$ The majority of inventions in the pharmaceutical industry are patented (Arundel and Kabla, 1998; Campbell, 2005) and firm-specific patent application policies are likely to be relatively stable over time.
} 
SEC in the US, and, for Japanese firms, information on foreign subsidiaries published by Toyo Keizai in the yearly 'Directories of Japanese Overseas Investments', were used. The consolidation was conducted on a yearly basis to take into account changes in the group structure of sample firms due to acquisitions, mergers, green-field investments and spin-offs. Acquisitions are considered part of a parent firm from the year the acquisition transaction has been completed.

Patent data are taken from the European Patent Office (EPO). The technological performance of the sample firms (dependent variable) is measured as the number of EPO patent applications of a parent firm in a year, weighted by the number of forward patent citations received by those patents over a fixed time window of 4 years. The number of forward patent citations is calculated on a fixed time window because the number of forward citations to any patent depends on the length of the citation window (Hall et al, 2005; Trajtenberg, 1990). Forward patent citations are calculated on the EPO patent citation database described in Webb et al. (2005) and are calculated for all citing EPO patents and national patents with EPO patent equivalents.

\section{Internal Basic Research}

We used information on scientific publications authored by the sample firms and published in peer reviewed international journals to assess the internal basic research activities of firms. Publication data are extracted from yearly updates of the Science Citation Index database of ISI/Thomson Scientific; documents of the type article, letter, note and review have been selected. Publication data is collected at the consolidated parent firm level, following a similar approach as the one followed for the collection of patent data. This approach consists of identifying all publications on which the parent firms, or their subsidiaries, are listed as publishing institutes. The consolidation exercise is conducted annually. In line with studies of Hicks et al (1994) and Cockburn and Henderson (1998) we find that pharmaceutical firms publish extensively; the sample firms published on average 263 publications per year in the SCI database over the period 1995-2002. We collected bibliographic information (journal name, volume, pages etc.) for all the publications on which the 33 sample firms are listed as one of the authors' institutions.

We classified a publication as 'basic research' based on the journal in which it is published and the CHI journal classification scheme which classifies each of the SCI journals in one of four 
research levels, in a spectrum ranging from very applied, targeted research to basic research. For biomedical journals the four different research levels are called 'clinical observation’ (level 1), 'clinical mix' (level 2), 'clinical investigation' (level 3) and 'basic biomedical research’ (level $4)^{5}$. Journals that are classified in level 4 are considered as reporting mainly basic research findings. About $36 \%$ of the SCI publications of the sample firms are published in basic research journals. The remaining $64 \%$ of SCI publications report on applied research activities of the sample firms (clinical trials) and are not used in the construction of the internal basic research variables.

The internal basic research variable is constructed on the basis of a 4-year moving time window. The internal basic research expertise of a firm in year $t$ is measured as the sum of firm publications that are published in basic research journals in the past 4 years (t-4 to t-1) by firm subsidiaries that were part of the parent firm in year t. The variable is divided by the size of the firm's $R \& D$ expenditures in year t- 1 to make it independent of the scale of the firm's $R \& D$ activities, in line with prior work of Cockburn and Henderson (1998) and Fabrizio (2009).

Following prior work by Cockburn and Henderson (1998) and Fabrizio (2009), the intensity of collaboration between the firm and university scientists in basic research is measured as the share of firm publications in basic research journals that are co-authored with universities. To identify firm publications that are jointly written with university scientists we coded the presence of the words university, college or regents in the publishing institutes names of firms' publications.

\section{Exploitation of External Basic Research}

Our measure of the exploitation of external basic research findings in firms' technology activities is based on references in the prior art of firms' patents to publications in basic research journals (not published by the firm itself). The prior art section of a patent contains references to prior patents and non-patent literature, including scientific articles. The legal purpose of the references is to indicate which parts of the knowledge described can be claimed by the patent and which parts have been claimed by other patents and non-patents. Patent references restrict the scope of

\footnotetext{
${ }^{5}$ An example of a journal that is classified in level 1 is the Journal of the American Medical Association. The Journal of Biological Chemistry is an example of a journal that is classified in level 4 (Hamilton, 2003).
} 
patent claims to novelty and represent a link to the pre-existing knowledge base upon which patents have been built (Criscuolo and Verspagen, 2008; Jaffe et al, 2004). This feature has been used by prior studies (e.g. Narin et al, 1997; Fleming and Sorenson, 2004) to justify the use of patent references as information source on the knowledge base of patent applicants.

One critique to this particular use of patent references is that the prior art section of patents includes references provided by patent applicants while filing their patents as well as references added later on by patent examiners during their search for relevant prior art (Alcacer and Gittelman, 2006). The problem is that patent applicants may not know part of the references cited in the prior art of their patents, especially references made by patent examiners (Brusoni et al, 2005). However, surveys of USPTO patent inventors (Jaffe et al, 2004; Fleming and Sorenson, 2004; Tijssen et al, 2000) have shown that inventors are aware of a significant part of the patents and scientific articles that are cited in the prior art of their patents, including some of the references made by patent examiners ${ }^{6}$. Using data on EPO patents and responses to the Community Innovation Survey (CIS) for a sample of French firms, Duguet and MacGarvie (2005) find a positive correlation between the number of references in firms' patents and the intensity to which firms have sourced external knowledge. We consider this sufficient evidence to take scientific references on patents as an (although imperfect) indicator of the knowledge base that firms have drawn on, or at least had an awareness of, in their technology activities.

Non-patent references were extracted for all EPO patents of the sample firms, using information from the patents' search reports. Patents cite a variety of non-patent references, such as scientific articles, books, newspapers, company reports and industry related documents, which do not all refer to basic research findings (Harhoff et al, 2003; Callaert et al, 2006). We have used nonpatent references to scientific articles in basic research journals in the calculation of our firmlevel indicator of the usage of external basic research. These references are identified via a text-

\footnotetext{
${ }^{6}$ In a survey of USPTO patent inventors, Jaffe et al (2004) find that patent inventors have a moderate to high familiarity with more than $50 \%$ of the cited patent references. Given that, on average, $63 \%$ of patent references in USPTO patents are provided by patent examiners (Alcacer and Gittelman, 2006), this shows that patent applicants are also aware of part of the patent references that are added by patent examiners. Among all references on patents, references to scientific articles are more frequently added by patent applicants themselves (Narin and Noma, 1985; Jaffe et al, 1998), which explains a much higher degree of familiarity of patent inventors with scientific articles cited on their patent documents: Fleming and Sorenson (2004) and Tijssen et al (2000) report that patent inventors are aware of $62 \%$ and $84 \%$ of the cited articles in their patents, in their respective surveys.
} 
matching algorithm and the CHI list of all research journals (applied/basic) in the SCI database. Specifically, non-patent references (NPRs) to scientific articles in the SCI database are identified by checking for the presence of SCI journal names (6,400 journals) in the text strings of the NPRs on the patent documents. Patents of our sample firms cited on average 1,62 non-patent references in their prior art section. About $70 \%$ of these non-patent references referred to publications in scientific journals (SCI database); 40\% of these non-patent references referred to publications in basic research scientific journals. These numbers are comparable with numbers found in prior studies on the nature of non-patent references (Harhoff et al., 2003; Callaert et al., 2006).

Since we want to measure the exploitation of external basic research findings in firms' $R \& D$ activities, references to basic research publications authored by the firm itself have to be removed from our indicator. On average, $7 \%$ of the citations to publications in basic research journals referred to publications of the citing firm. We identified NPRs to publications of the firm itself by retrieving (for all scientific NPRs) information on the volume, year and starting page of the publication to which the NPRs refer. An NPR was considered to refer to a publication of the firm itself when the journal name, volume, year and starting page in the NPR text were identical to one of the publications identified as authored by the firm.

In parallel with the internal basic research variable, our measure of the exploitation of external basic research findings in firms' technology activities is also computed on a 4 year moving window. More specifically, the exploitation of external basic research variable is calculated as the average number of citations to publications in basic research journals (not belonging to the firm itself) in patents that are applied for by the firm (subsidiaries of the firm in year $\mathrm{t}$ ) in the past 4 years ( $t-4$ to $t-1)$. The variable is expressed as an intensity to make it independent of the scale of firms' technology activities for which the analysis controls separately.

\section{Control Variables}

Our empirical models control for other (time varying) firm-level factors that are likely to impact on firms' technological performance. First, we control for differences in the scale of the firms' R\&D expenditures, taking a one-year time lag between $R \& D$ expenditures and firm patents. The data on firms' R\&D expenditures are collected from corporate annual financial reports 
(Worldscope and Compustat databases) and are measured in millions of US dollars. Second, we control for differences in the prior patent productivity of firms, measured as the one-year lagged ratio of the number of firm patents to $R \& D$ expenditures. Third, we include an indicator for the level of technology diversification in a firm's patent portfolio such that both scale and scope of R\&D activities of firms are controlled for (Arora et al, 2009, Henderson and Cockburn, 1996; Nesta and Saviotti, 2005). Technology diversification is measured as the 'spread' of patents in a firm's 4-year patent portfolio over technology classes. Technology class information on patents is derived from the IPC classes assigned to patents. We distinguished between 120 different 3digit IPC classes to construct the diversification measure. The technology diversification variable is the inverse of the so-called Herfindahl index: it takes higher values when the level of technology diversification increases. Both linear and quadratic terms of technology diversification are included in the regression model to test for the existence of an inverted Ushape relationship between technology diversification and firm technological performance (e.g. Henderson and Cockburn, 1996; Leten et al, 2007). Finally, the empirical models include time dummies (1995 as base category) to account for time-specific factors affecting the technological performance (forward citation weighted patent numbers) of the sample firms.

\section{Methods}

The dependent variable (citation-weighted patent count) is a count variable with only nonnegative integer values. In this case, nonlinear count data models are preferred to standard linear regression models as they explicitly take into account the non-negativity and discreteness of the dependent variable. Negative Binomial count data models, which control for over-dispersion in the dependent variable, are used (Cameron and Trivedi, 1998). We have used fixed effects panel data estimators in all regression models to control for unobserved (time-invariant) firm characteristics; such as R\&D management capabilities, that could affect technological performance. Besides including fixed-effects, our empirical specification has other features that alleviate concerns of potential endogeneity and biases stemming from unobserved factors. First, the temporal ordering of the variables in the model - where past publication and NPR counts are included to explain current performance - avoids reverse causality where higher innovation performance and the ensuing higher availability of $R \& D$ resources may lead to more internal basic research and more frequent exploitation of external basic research. Second, we include several key time-varying firm characteristics 
as control variables (R\&D expenses, patent intensity, and technology diversification) that are likely to pick up time variant firm traits such as developments in corporate $R \& D$ resources and capabilities.

\section{Summary Statistics}

Summary statistics of the dependent and explanatory variables can be found in Table 1 . There is substantial variation between the sample firms in the internal and external basic research variable, with maximum values being several times larger than the minimum and mean values. The sample firms do actively collaborate with universities in internal basic research activities; the percentage of internal basic research publications that are co-authored with universities is on average $46 \%$, while it ranges from $11 \%$ to $78 \%$.

Insert Table 1 about here

Table 2 reports the coefficients of correlation between the variables of interest. As to be expected, the correlation between technology diversification and its squared term is considerable; none of the other reported correlations is excessively high. There is a positive correlation between internal and external basic research. This suggests that firms which conduct more internal basic research do more actively exploit external basic research findings in their technology activities, providing first evidence of the complementary character of both activities.

Insert Table 2 about here

Figure 1 shows the internal and external basic research activities for the sample firms, measured as the firm's average number of publications per year and the firm's average number of NPRs per year, respectively. While the positive correlation between the two types of basic research is apparent, the figure also illustrates that the firms are heterogeneous in their focus on internal versus 
external basic research. For example, whilst both companies on average make a comparable number of citations to external basic research in their patents (about 130), the research strategy of Novartis places relatively more emphasis on internally performed basic research than BristolMyers Squibb in terms of publications in basic research journals (630 versus 340).

Insert Figure 1 about here

Finally, Figure 2 shows the evolution in internal and external basic research activities over the sample period. The average basic research publication activity across firms has remained roughly constant. ${ }^{7}$ Turning to the citations to (non-firm) basic research publications on firm patents, there is a clear increasing trend, in line with the findings of Narin et al. (1997).

Insert Figure 2 about here

\section{Empirical Results}

The empirical results of the fixed effects Negative Binomial regression models of the relationship between internal basic research, the exploitation of external basic research findings and the technological performance of firms are reported in Table 3. Model 1 includes only the control variables and acts as point of comparison for the other models. The R\&D expenditures and patent intensity variables have the expected positive signs and are both statistically significant. Technology diversification has a positive linear term, and a negative quadratic term. The linear term is significant in all models; the quadratic term is only significant in the most complete model 5. These results confirm the existence of an inverted U-shape relationship

\footnotetext{
${ }^{7}$ By comparison, Gambardella (1992) reported figures on the whole of basic and applied publications by a small number of US pharmaceutical firms in the period 1973-1986. He observed a significant upward trend for some firms (e.g. Merck), but not for all (e.g. Eli Lilly).
} 
between technology diversification and firms' technological performance. The peak of the inverted U-shaped curve occurs at a value of 4,78 (calculation done for model 5), with 19\% of the sample firms having larger values for the technology diversification variable.

Insert Table 3 about here

The external basic research variable is positive and significant in model 2, showing that firms can increase their technological performance by exploiting more external basic research findings in their technology activities. When the internal basic research variable is added to the model (model 3), its coefficient is positive and significant, while the coefficients of the other variables do not change materially. This confirms that internal basic research has a positive impact on firms' technological performance. The magnitude of the impact of internal and external basic research on firms' technological performance can be derived directly from the estimated coefficients of both basic research variables, which can be interpreted as semi-elasticities. Both variables have a similar semi-elasticity: a one-unit change in basic research (which implies roughly 2 standard deviations change) increases firm performance by 33 percent. The coefficient of the variable 'collaboration with universities in internal basic research' is positive and significant coefficient when added (model 4), which implies that internal basic research has a larger positive impact on firms' technological performance when it is conducted in collaboration with universities.

In the final model (model 5), the interaction effect between internal basic research and the exploitation of external basic research is added to the analysis. ${ }^{8}$ The coefficient of the interaction variable is positive and significant, while the coefficients of both main effects also remain positive and significant. In non-linear regression models such as the Negative Binomial model, the sign and significance of the interaction variable is however no definitive indication of the sign and significance of the interaction effect (Hoetker, 2007). The interaction effect, in which

\footnotetext{
${ }^{8}$ The interaction effect is created as the product of the demeaned values of internal basic research and the exploitation of external basic research. This approach allows evaluating the main effects of both basic research variables at 'meaningful' values (mean value of the other basic research variable) rather than at the level zero.
} 
we are interested, is calculated as the partial cross-derivative of the conditional mean function of the fixed effect Negative Binomial model with respect to both variables (internal basic research and usage of external basic research). We calculated the value of the cross-derivative function for all sample observations. The coefficient for the cross-derivate took positive values for all 245 sample observations and was significant at $10 \%$ level for 244 of the 245 observations. These results provide strong support for the notion of a complementary relationship between internal basic research and the exploitation of external basic research findings.

One way to illustrate the magnitude of the complementary effects of internal and external basic research on firm technological performance is to depict the value of the predicted citationweighted patents (on the vertical axis) for different combinations of internal and external basic research (Figure 3; the other regressors are taken at their sample means). The values for internal and external basic research vary within one standard deviation from their mean. The surface plot in Figure 3 confirms the main effects of internal and external basic research, and more importantly, illustrates the magnitude of the interaction effect of both variables. Clearly, it is the joint increase in internal and external basic research that has the dominant influence on firms' technological performance. For firms with a low internal basic research capability, an increase of the usage of external basic research from low to high values increases the firm's technological performance (patent output) by 7 percent (from 75 to 80); while for firms with a strong internal research capability patent output increases by 78 percent (from 99 to 176). These observations clearly illustrate the importance of pursuing internal basic research activities and the sourcing of external basic research findings simultaneously. These results, in combination with the heterogeneous basic research strategies adopted by firms (Figure 1) and the rise in the exploitation of external basic research without a commensurate increase in internal basic research (Figure 2), may suggest that there are firms that could increase their performance by developing stronger internal basic research capabilities. In addition to a direct positive effect on technological performance, this would increase the return of the usage of external basic research.

Insert Figure 3 about here 


\section{Conclusions}

This paper examined the effects of basic research on the technological performance of firms in the pharmaceutical industry. We extended prior studies by jointly examining the impact of basic research performed by the firms in-house (internal basic research) and the usage of external basic research findings in firms' R\&D activities (exploitation of basic research performed elsewhere). We explicitly tested for the potentially complementary character of both types of basic research activities. We analyzed the effects of firms' basic research strategies drawing on a panel dataset (1995-2002) on the R\&D, patent and publication activities of 33 large American, European and Japanese firms in the pharmaceutical industry. Internal basic research activities are measured by publications in basic research journals in which the firm or its subsidiaries are listed as the host institution of the authors. The exploitation of external basic research findings in firms' technology activities is captured by references to web of science publications in basic research journals (excluding references to firms' own publications) in the prior art of firms' patents,

Fixed-effects panel data analyses confirmed that engagement in internal basic research activities improves technological performance, in particular when these research activities are undertaken in close collaboration with universities. This finding is consistent with the 'connectedness' idea put forward in Cockburn and Henderson (1998), which states that research collaboration with university scientists offers opportunities for intense debate, discussion, and exchange of valuable tacit knowledge, which can improve the quality and impact of firms’ R\&D activities. In addition, we find clear evidence that firms can increase their technological performance by more actively exploiting external basic research findings in their technology activities. The magnitude of the effect of external basic research exploitation is significantly greater if firms conduct more internal basic research. Hence, internal basic research activities and the exploitation of external basic research findings are complementary R\&D strategies for firms. This complementarity is the dominant influence in the basic research - technological performance relationship, with the predicted effect of external basic research more than 10 times larger for firms with the strongest internal research capabilities as compared to firms with little internal basic research. These results, against the background of heterogeneous basic research strategies adopted by firms and the observed rise in the exploitation of external basic research without a commensurate increase 
in internal basic research, suggest that there are pharmaceutical firms that could increase their technological performance by developing stronger internal basic research capabilities.

Our analysis shows that internal basic research has both direct and indirect positive effects on firms' technological performance. Internally conducted basic research provides firms with a deeper understanding of the phenomena under research, which on the one hand improves the efficiency of their technology activities, and on the other hand helps to monitor, interpret and utilize findings emanating from basic research that is conducted outside the firms. This indicates that external basic scientific knowledge is not a perfect public good and that firms need to invest in a sufficient 'absorptive capacity' to benefit fully from external basic research findings in their own technology activities. The observation that basic scientific knowledge is not freely available to all firms, but only to those who have the right background knowledge and skills, is consistent with Rosenberg's (1990) perspective on the economics of basic research. Building up and maintaining this 'absorptive capacity' is however not easy or inexpensive to accomplish. It has major organizational consequences, as it involves hiring (top)-scientists and granting them the freedom to conduct basic research, preferably in collaboration with universities in the context of scarce firm R\&D resources (Pavitt, 1991; Gambardella, 1992; Cockburn and Henderson, 1998).

Our research had a number of limitations, which suggest fruitful directions for future research. Our findings on the role of basic research relate to firms in the pharmaceutical industry and one should be careful to generalize our findings to firms in other sectors. The pharmaceutical industry is exceptional with respect to the relevance of basic research for technology activities (McMillan et al, 2000; Rosenberg, 1990) and appropriability conditions due a high efficacy of patenting (Lim, 2004). However, we suspect that our results do have relevance to firms in other industries in which basic research and technology development are closely linked, such as semiconductors and electronics (Pavitt, 1984; Klevorick et al, 1995). The investigation of the relationship between basic research and firm performance in other industries is an interesting direction for further research. A second avenue for future research is examining more in detail the organizational characteristics of firms' basic research activities. Rosenberg (1990) suggests that corporate basic research is likely sterile and unproductive if it is conducted in a separate unit isolated from the rest of the firm's R\&D activities. The effectiveness of basic research is 
expected to increase if it is conducted in close interaction with the work and interests of the firms' engineers. One way to examine these interactions may be to analyze collaboration and citation patterns of corporate scientists and engineers, using, for example, information that is available in the firms' patent and publication data. 


\section{References}

Adams J.D. (1990). Fundamental stocks of knowledge and productivity growth. Journal of Political Economy, 98, 673-702.

Alcacer J. and Gittelman M. (2006). Patent citations as a measure of knowledge flows: The influence of examiner citations. The Review of Economics and Statistics, 88(4), 774-779.

Allen T. (1977). Managing the flow of technology. MIT Press, Cambridge (MA).

Arora A. and Gambardella A. (1990). Complementarity and external linkages: The strategies of the large firms in biotechnology. The Journal of Industrial Economics, 38(4), 361-379.

Arora A., Gambardella A., Magazinni L. and Pammili F. (2009). A breath of fresh air? Firm type, scale, scope and selection effects in drug development. Management Science, 55(10), 1638-1653.

Arrow K. (1962). Economic welfare and the allocation of resources for invention. In Nelson R. (Ed). The Rate and Direction of Inventive Activity (Princeton University Press, New Jersey).

Arundel A. and Kabla I. (1998). What percentage of innovations are patented? Empirical estimates from European firms. Research Policy, 27, 127-141.

Basberg B. (1987). Patents and the measurement of technological change: A survey of the literature. Research Policy, 16, 131-141.

Brusoni S., Criscuolo P. and Guena A. (2005). The knowledge bases of the world's largest pharmaceutical groups: What do patent citations to non-patent literature reveal? Economics of Innovation and New Technologies, 14 (5), 395-415.

Campbell J.J.(2005). Understanding Pharma. A Primer on How Pharmaceutical Companies Really Work. Pharmaceutical Institute, Inc., Raleigh, NC.

Callaert J., Van Looy B., Verbeek A., Debackere K. and Thijs, B. (2006). Traces of prior art: An analysis of non-patent references found in patent documents. Scientometrics, 69(1) 3-20.

Cameron A. and Trivedi P. (1998). Regression analysis of count data. Cambridge University Press, Cambridge.

Cassiman, B., \& Veugelers, R. (2006). In search of complementarity in innovation strategy: Internal R\&D and external knowledge acquisition. Management Science, 52(1), 68-82.

Cassiman B., Veugelers R. and Zuniga M.P. (2008). In search of performance effects of (in)direct industry-science links. Industrial and Corporate Change, 17(4), 611-646. 
Cockburn, I. and Henderson R., (1998). Absorptive capacity, coauthoring behavior, and the organization of research in drug discovery. The Journal of Industrial Economics, 46(2), 157182.

Cohen W. and Levinthal D. (1990). Absorptive capacity: A new perspective on learning and innovation. Administrative Science Quarterly, 35, 128-152.

Criscuolo P. and Verspagen B. (2008). Does it matter where patent citations come from? Inventor versus examiner citations in European patents. Research Policy, 37, 1892-1908.

Duguet E. and MacGarvie M. (2005). How well do patent citations measure flows of technology? Evidence from French innovation surveys. Economics of Innovation and New Technologies, 14, 375-394.

Fabrizio K.R. (2009). Absorptive capacity and the search for innovation. Research Policy, 38(2), 255-267.

Fleming L., and Sorenson O. (2004). Science as a map in technological search. Strategic Management Journal, 25, 909-928.

Furukawa R. and Goto A. (2006). The role of corporate scientists in innovation. Research Policy, 35, 24-36.

Gambardella A. (1992). Competitive advantages from in-house scientific research: the U.S. pharmaceutical industry in the 1980s. Research Policy, 21, 391-407.

Gambardella A., Harhoff D. and Verspagen B. (2008). European Management Review, 5(2), 6984.

Gibbons M. and Johnston R. (1974). The roles of science in technological innovation. Research Policy, 3, 220-242.

Griliches Z. (1986). Productivity, R\&D and basic research at the firm level in the 1970s. The American Economic Review, 76(1), 141-154.

Griliches Z. (1990). Patent statistics as economic indicators - a survey. Journal of Economic Literature, 28(4), 1661-1707.

Hall B., Jaffe A. and Trajtenberg M. (2005). Market value and patent citations. Rand Journal of Economics, 36(1), 16-38.

Hamilton K. (2003). Subfield and level classification of journals. CHI Report No. 2012-R.

Harhoff D., Narin F., Scherer F. And Vopel K. (1999). Citation frequency and the value of patented inventions. Review of Economics and Statistics, 81(3), 511-515. 
Harhoff D., Scherer F. and Vopel K. (2003). Citations, family size, opposition and the value of patent rights. Research Policy, 32, 1343-1363.

Helfat C. (1994). Evolutionary trajectories in petroleum firm R\&D. Management Science, 40(12), 1720-1747.

Henderson R. and Cockburn I. (1994). Measuring competence? Exploring firm effects in pharmaceutical research. Strategic Management Journal, 15, 63-84.

Henderson R. and Cockburn I. (1996). Scale, scope and spillovers: The determinants of research productivity in drug discovery. Rand Journal of Economics, 27(1), 32-59.

Hicks D., Ishizuka T., Keen P and Sweet S. (1994). Japanese corporations, scientific research and globalization. Research Policy, 23, 375-384.

Hicks D. (1999). Six reasons to do long term research. Research - Technology Management, July/August, 8-11.

Hoetker G. (2007). The use of Logit and Probit models in strategic management research: Critical issues. Strategic Management Journal, 28, 331-343.

Jaffe A. (1989). Real effects of academic research. American Economic Review, 79(5), 957-970.

Jaffe A., Fogarty M. and Banks B. (1998). Evidence from patents and patent citations on the impact of NASA and other federal labs on commercial innovation. The Journal of Industrial Economics, 66(2), 183-205.

Jaffe A., Trajtenberg M. and Fogarty M. (2004). Knowledge spillovers and patent citations: Evidence from a survey of inventors. American Economic Review, 90(2), 215-218.

Klevorick, A.K., Levin, R., Nelson, R., Winter, S., 1995. On the sources and significance of inter-industry differences in technological opportunities. Research Policy, 24, 185-205.

Lanjouw J., Pakes A. and Putnam J. (1998). How to count patents and value intellectual property: the use of patent renewal and application data. The Journal of Industrial Economics, 66(4), 405-432.

Leten B., Belderbos R. and Van Looy B. (2007). Technological diversification, coherence and performance of firms. The Journal of Product Innovation Management, 24(6), 567-579.

Liebeskind J.P., Oliver A.L., Zucker L. and Brewer M. (1996). Social networks, learning, and flexibility: sourcing scientific knowledge in new biotechnology firms. Organization Science, 7(4), 428-442. 
Lim K. (2004). The relationship between research and innovation in the semiconductor and pharmaceutical industries (1981-1997). Research Policy, 33, 287-321.

Lokshin B., Belderbos R. and Carree M. 2008. The productivity effects of internal and external R\&D: Evidence from a dynamic panel data model. Oxford Bulletin of Economics and Statistics, 70(3), 399-413.

McMillan, G.S., Narin, F., Deeds, D.L., 2000. An analysis of the critical role of public science in innovation: the case of biotechnology. Research Policy, 29, 1-8.

Mansfield E. (1980). Basic research and productivity increase in manufacturing. The American Economic Review, 70(5), 863-873.

Mansfield E. (1995). Academic research underlying industrial innovations: sources, characteristics and findings. The Review of Economics and Statistics, 77, 55-65.

Mansfield E. (1998). Academic research and industrial innovation: An update of empirical findings. Research Policy, 26, 773-776.

Matutes C., Regibeau P. and Rockett K. (1996). Optimal patent design and the diffusion of innovations. Rand Journal of Economics, 27(1), 50-83.

Narin F. and Noma E. (1985). Is technology becoming science? Scientometrics, 7, 369-381.

Narin F. and Olivastro D. (1992). Status report - linkage between technology and science. Research Policy, 21(3), 237-249.

Narin F. and Breitzman A. (1995). Inventive productivity. Research Productivity, 24, 507-519.

Narin F., Hamilton K., Olivastro D. (1997). The increasing linkage between U.S. technology and public science. Research Policy, 26, 317-330.

Nelson R. (1959). The simple economics of basic scientific research. The Journal of Political Economy, 67(3), 297-306.

Nelson R. (1962). The link between science and invention: The case of the transistor, in Nelson R. (Ed) The Rate and Direction of Inventive Activity (Princeton University Press, New Jersey).

Nesta L. and Saviotti P. (2005). Coherence of the knowledge base and the firms' innovative performance: Evidence from the U.S. pharmaceutical industry. The Journal of Industrial Economics, 53(1), 123-142.

National Science Foundation (2009). Business R\&D and Innovation Survey. 
Pavitt K. (1984). Sectoral patterns of technical change - Towards a taxonomy and theory. Research Policy, 13(6), 343-373.

Pavitt K. (1985). Patent statistics as indicators of innovative activity: Possibilities and problems. Scientometrics, 7(1), 77-99.

Pavitt K. (1991). What makes basic research economically useful? Research Policy, 20, 109-119.

Pisano G. (1997). The development factory. Harvard Business School Press, Boston, MA.

Rosenberg N. (1990). Why do firms do basic research (with their own money)? Research Policy, 19(2), 165-174.

Salter A. and Martin B. (1990). The economic benefits of publicly funded research: A critical review. Research Policy, 30, 509-532.

Stephan P.E. (1996). The economics of science. Journal of Economic Literature, 34(3), 11991235.

Stern S. (2004). Do Scientists Pay to Be Scientists? Management Science, 50(6), 835-853.

Teece D., Pisano G. and Shuen A. (1997). Dynamic capabilities and strategic management. Strategic Management Journal, 18(7), 509-533.

Tijssen R.J.W., Buter R.K. and van Leeuwen Th.N. (2000). Technological relevance of science: An assessment of citation linkages between patents and research papers. Scientometrics, 47(2), 389-412.

Trajtenberg M. (1990). A penny for your quotes: Patent citation and the value of innovation. Rand Journal of Economics, 21, 172-187.

Webb C., Dernis H., Harhoff D. and Hoisl K. (2005). Analyzing European and international patent citations: A set of EPO patent database building blocks. OECD Science, Technology and Industry Working Papers, 2005/9, OECD Publishing.

Zucker L., Darby M. and Armstrong J. (2002). Commercializing knowledge: University science, knowledge capture, and firm performance in biotechnology. Management Science, 48(1), 138-153. 


\section{Tables}

\section{Table 1: Descriptive Statistics}

\begin{tabular}{lcccc}
\hline $\mathrm{N}=$ 245 & Mean & St. Dev. & Min & Max \\
\hline Citation Weighted Patent Count & 136.85 & 154.67 & 1 & 651 \\
R\&D Expenses (million \$) & 791.51 & 856.90 & 21.70 & 4847 \\
Patent Intensity (patents per million \$ R\&D) & 0.16 & 0.17 & 0.02 & 1.04 \\
Technology Diversification & 3.36 & 0.94 & 1.70 & 5.69 \\
External Basic Research (NPRs per patent) & 0.75 & 0.45 & 0.08 & 2.33 \\
Internal Basic Research (publications per million \$ R\&D) & 0.60 & 0.60 & 0.04 & 4.27 \\
Fraction Internal Basic Research with Universities & 0.46 & 0.12 & 0.11 & 0.78 \\
\hline
\end{tabular}

\section{Table 2: Correlation Coefficients}

\begin{tabular}{lccccccccc}
\hline $\mathrm{N}=245$ & 1 & 2 & 3 & 4 & 5 & 6 & 7 & 8 & 9 \\
\hline 1 Citation Weighted Patent Count & 1 & & & & & & & & \\
2 log (R\&D Expenses) & 0.63 & 1 & & & & & & \\
3 Patent Intensity & 0.12 & -0.45 & 1 & & & & & \\
4 Technology Diversification & 0.10 & -0.07 & 0.47 & 1 & & & & & \\
5 Technology Diversification & & 0.08 & -0.10 & 0.48 & 0.99 & 1 & & & \\
6 External Basic Research & -0.25 & -0.21 & -0.06 & 0.23 & 0.17 & 1 & & & \\
7 Internal Basic Research & 0.26 & -0.17 & 0.56 & 0.25 & 0.22 & 0.10 & 1 & & \\
8 Share Internal BR with Universities & -0.24 & -0.17 & 0.08 & 0.18 & 0.17 & 0.25 & -0.24 & 1 & \\
9 Internal BR * External BR & -0.06 & -0.06 & -0.12 & -0.10 & -0.07 & -0.17 & -0.36 & -0.01 & 1 \\
\hline
\end{tabular}


Table 3: Fixed Effect Negative Binomial Regression of the Effects of Internal and External Basic Research on Firms’ Technological Performance

\begin{tabular}{|c|c|c|c|c|c|}
\hline & Model 1 & Model 2 & Model 3 & Model 4 & Model 5 \\
\hline \multirow[t]{2}{*}{ Log (R\&D Expenses) } & $0.23^{\star \star}$ & $0.24^{\star \star}$ & $0.29 * \star \star$ & $0.32^{\star \star \star}$ & $0.38^{\star \star \star}$ \\
\hline & $(0.11)$ & $(0.11)$ & $(0.10)$ & $(0.10)$ & $(0.10)$ \\
\hline \multirow[t]{2}{*}{ Patent Intensity } & $0.96^{\star \star}$ & $1.05^{\star \star \star}$ & $0.79^{\star \star}$ & $0.69 *$ & $0.70^{\star}$ \\
\hline & $(0.38)$ & $(0.39)$ & $(0.40)$ & $(0.40)$ & $(0.40)$ \\
\hline \multirow[t]{2}{*}{ Technology Diversification } & $0.62^{\star}$ & $0.61^{\star}$ & $0.63^{\star}$ & $0.62^{\star}$ & $0.67^{\star \star}$ \\
\hline & $(0.33)$ & $(0.34)$ & $(0.34)$ & $(0.34)$ & $(0.34)$ \\
\hline \multirow[t]{2}{*}{ Technology Diversification ${ }^{2}$} & -0.06 & -0.06 & -0.06 & -0.06 & $-0.07^{\star}$ \\
\hline & $(0.04)$ & $(0.04)$ & $(0.04)$ & $(0.04)$ & $(0.04)$ \\
\hline \multirow[t]{2}{*}{ External Basic Research } & & $0.33^{* *}$ & $0.33^{\star *}$ & $0.35^{\star \star \star}$ & $0.36^{\star \star *}$ \\
\hline & & $(0.13)$ & $(0.13)$ & $(0.13)$ & $(0.13)$ \\
\hline \multirow[t]{2}{*}{ Internal Basic Research } & & & $0.33^{\star \star \star}$ & $0.36 * \star \star$ & $0.44^{\star \star \star}$ \\
\hline & & & $(0.08)$ & $(0.08)$ & $(0.09)$ \\
\hline \multirow[t]{2}{*}{ Fraction Internal BR with Universities } & & & & $0.97^{\star}$ & $1.02^{\star \star}$ \\
\hline & & & & $(0.52)$ & $(0.51)$ \\
\hline \multirow[t]{2}{*}{ Internal BR * External BR } & & & & & $0.48^{\star \star}$ \\
\hline & & & & & $(0.21)$ \\
\hline Time Dummies & YES & YES & YES & YES & YES \\
\hline \multirow[t]{2}{*}{ Intercept } & -2.42 & $-2.74^{\star}$ & $-3.62^{\star \star}$ & 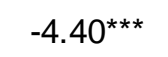 & $-4.80^{\star \star \star}$ \\
\hline & $(1.58)$ & $(1.56)$ & $(1.55)$ & $(1.54)$ & $(1.57)$ \\
\hline Number of Observations & 245 & 245 & 245 & 245 & 245 \\
\hline Number of Firms & 33 & 33 & 33 & 33 & 33 \\
\hline Wald Chi2 & $95.53^{\star \star *}$ & $103.27^{\star \star \star}$ & $125.36^{\star \star \star}$ & $131.26^{\star \star \star}$ & $140.20^{\star \star \star}$ \\
\hline Log Likelihood & -972.83 & -969.94 & -964.14 & -962.42 & -959.90 \\
\hline
\end{tabular}

Notes: Significance of coefficients is indicated by $*(0.1), * *(0.05)$ and $* * *(0.01)$. Standard errors are reported between parentheses. All models include firm-level fixed effects. 
Figure 1: Firm Heterogeneity in the Reliance on Internal and External Basic Research

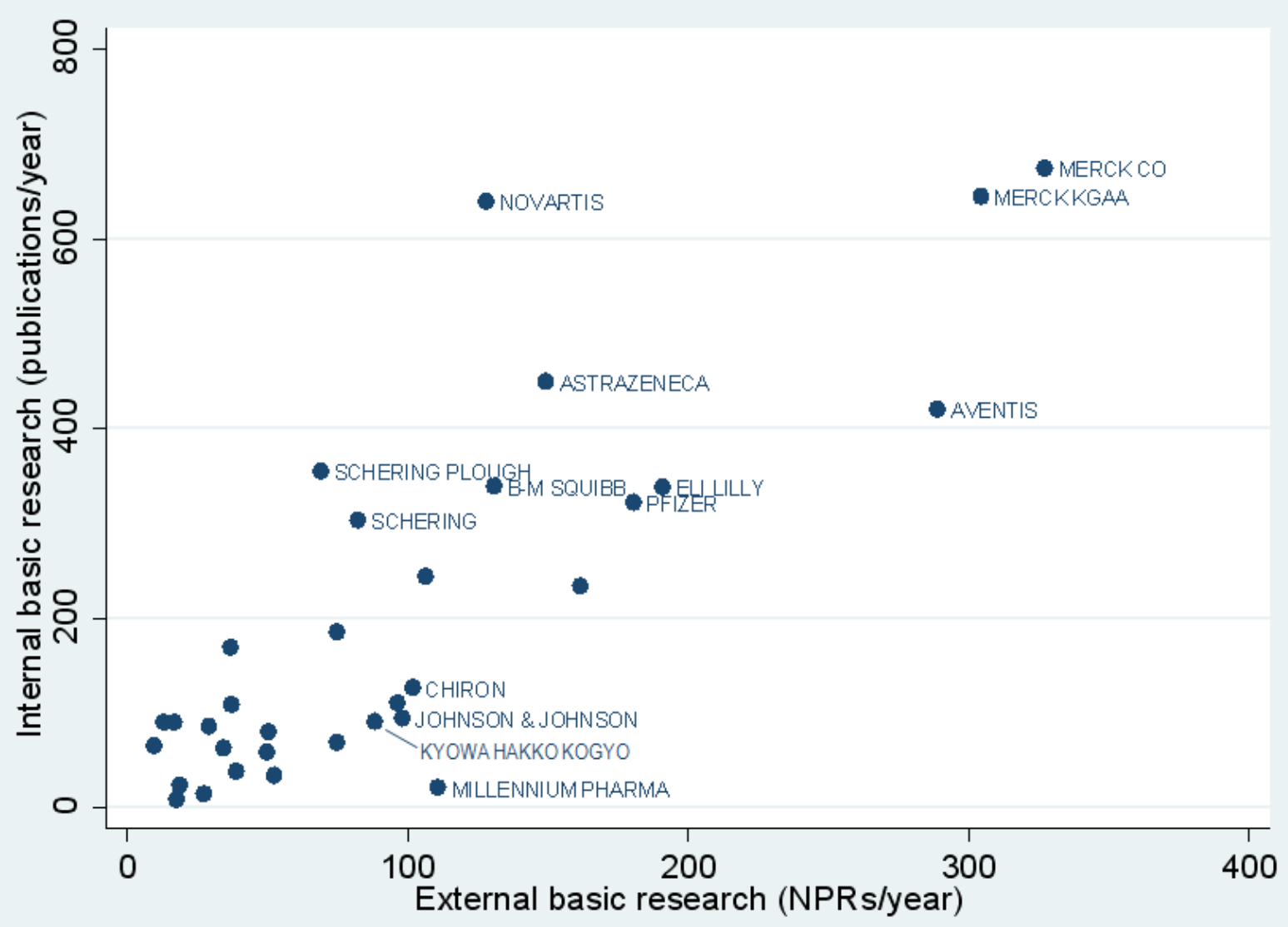


Figure 2: The Evolution of Internal and External Basic Research (averages across firms)

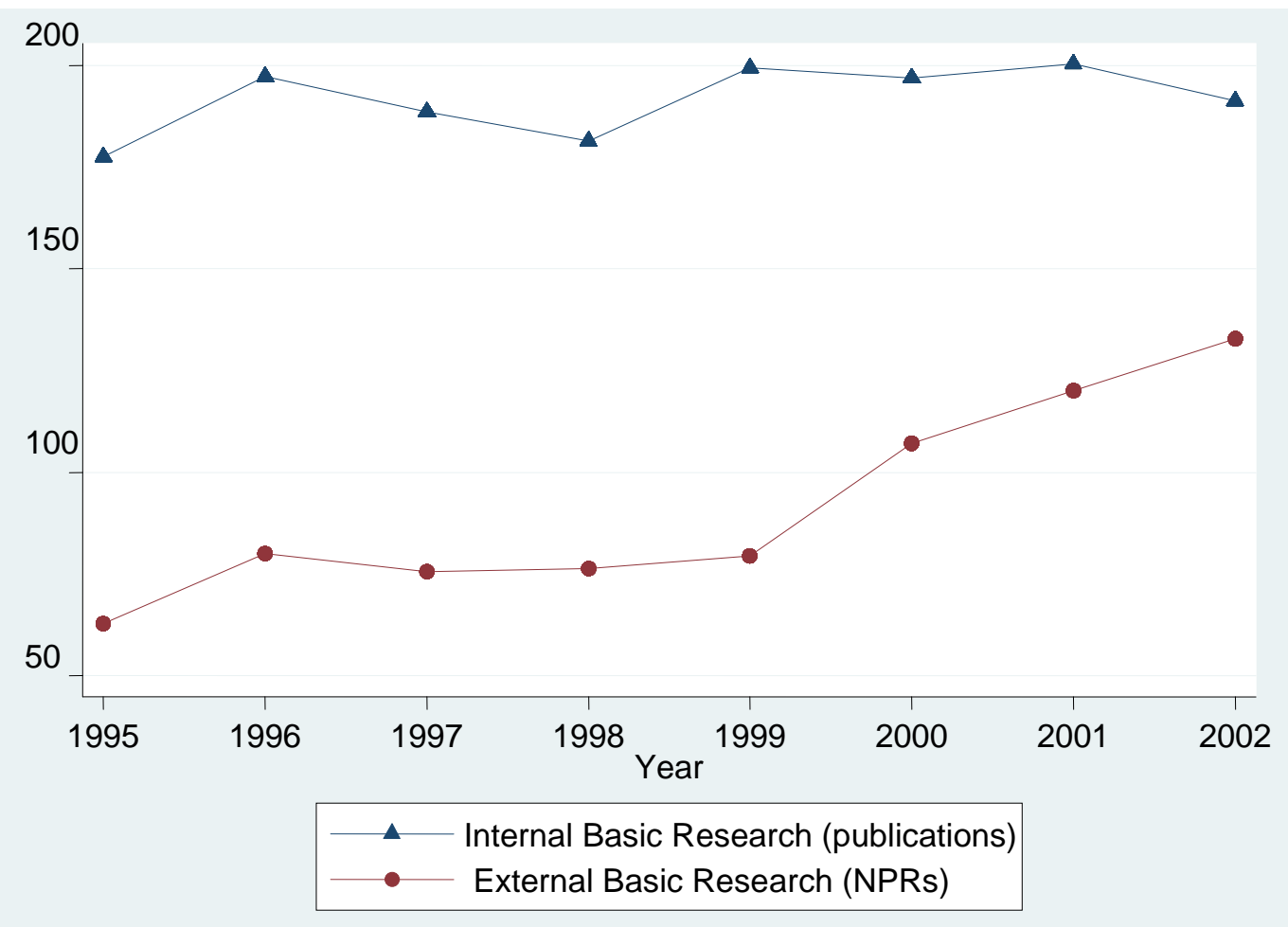


Figure 3: Predicted Technological Performance as a Function of Internal and External Basic Research

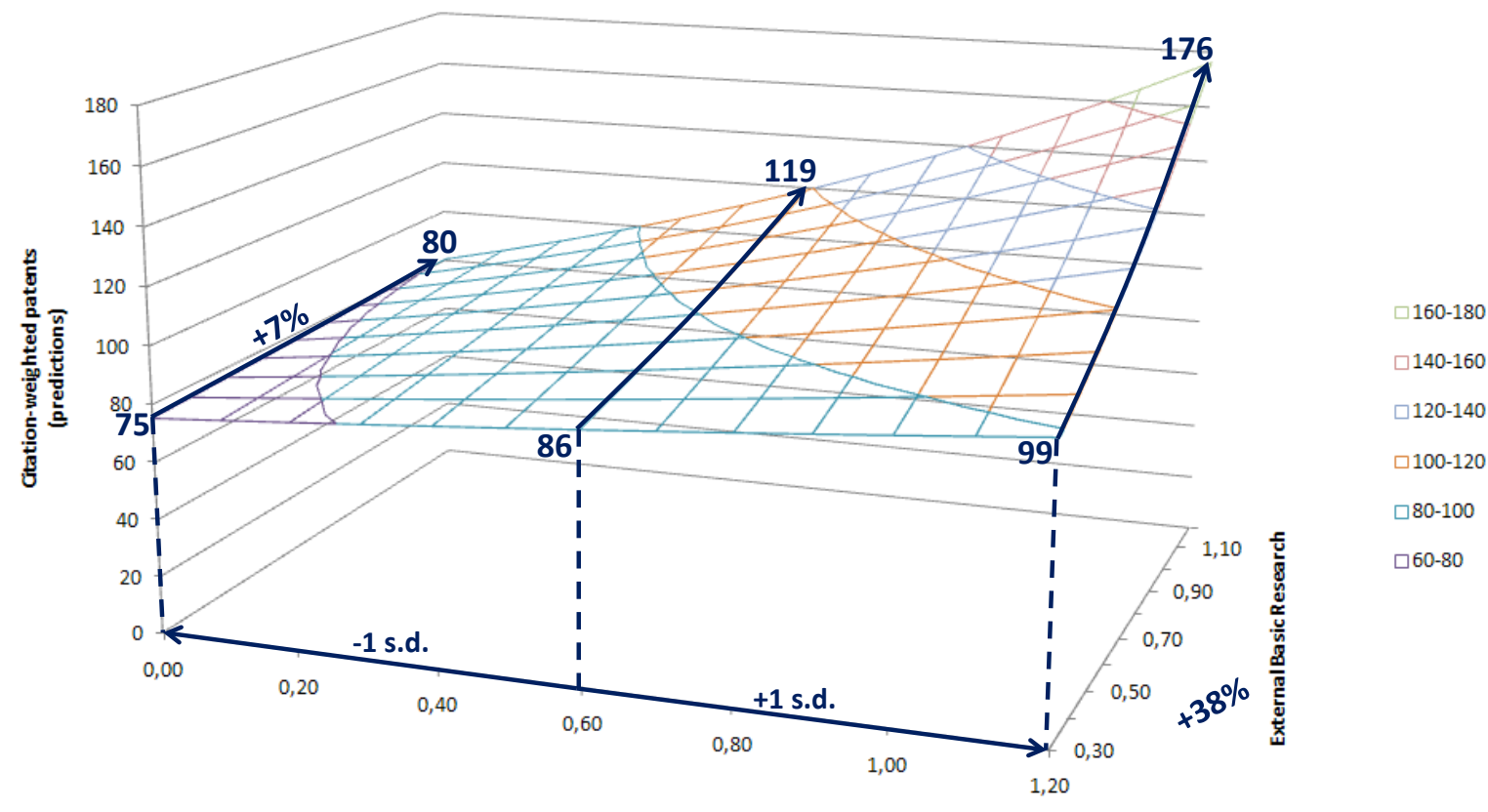

Note: Internal and external basic research take values within one standard deviation from the mean. Predictions are calculated at the means of the other independent variables. 